\title{
Inquiry-Based Learning in Cultural Studies
}

\author{
Margrit E. Kaufmann
}

In accordance with the subject of culture, the presentation of inquiry-based learning in cultural studies (Kulturwissenschaft) ${ }^{1}$ has multiple perspectives: The decentralized view of instructors and researchers is supplemented by the central perspective, in which the author (as an academic expert in diversity at the University of Bremen) participates in efforts to improve teaching and learning (Kaufmann 2013; Kaufmann \& Schelhowe in this volume; Satilmis in that volume).

\subsection{Characteristic Features in the Field of Cultural Studies as Basic Conditions for Inquiry-Based Learning}

In the last 20 years, cultural studies has been constituted and established as a transdisciplinary professional profile centered on cultural theories and concepts. This is reflected, among other things, in the fact that in 2014, upon the establishment of a "Cultural Studies Society" as a scientific association, an institutional framework was created for the subject. Degree programs in cultural studies are available, for example, in Bayreuth, Berlin, Bremen, Frankfurt/Oder, Lüneburg, Koblenz and Constance. This young subject is defined by its lack of clear disciplinary borders, because it crosses traditional subject-specific demarcations and approaches questions in a multi-perspective manner. This transdisciplinary, polyphonic interaction is largely based on cultural theories; the British concept of

\footnotetext{
${ }^{1}$ The German discipine "Kulturwissenschaft" is not congruent with the British concept of "Cultural Studies."
}

M. E. Kaufmann, Dr. $(\bowtie)$

Universität Bremen, Wissenschaftliche Expertin für Diversity der Universitätsleitung und

Fachbereich Kulturwissenschaften, Bremen, Germany

e-mail:mkaufm@uni-bremen.de

H. A. Mieg (ed.), Inquiry-Based Learning - Undergraduate Research, https://doi.org/10.1007/978-3-030-14223-0_25 
cultural studies; interpretive, postcolonial cultural anthropology; a proximity to literary studies; cultural history and cultures of remembrance, ethnopsychoanalysis; cultural mediation; intercultural and transcultural communication; postcolonial, gender and diversity studies; and media studies. In this sense, one often speaks of a plurality of cultural studies (Kulturwissenschaften). The subject matter of cultural studies research includes:

- the emphasis on processuality and the complexity of the cultural,

- everyday cultural phenomena and experiences,

- the interactions and relationships between cultural groups,

- the positioning of subjects within collectives with corresponding identity constructions and

- meaning and significance in the context of the change in macrostructural basic conditions.

That which is local is perceived within the context of globalization and transnationalization processes (Marcus 1998). Diversity and inequality research is one of the central areas of study and research in Bremen.

The behavior of "discovery," which is decisive for ethnography (Breidenstein et al. 2013, p. 13), is characteristic of the style of learning by doing research in cultural studies. This approach of discovery allows "lived experience" (according to Claude Lévi-Strauss) to be implemented by means of field research practices and methods. This has to do with the discipline-of-origin, ethnology, and its colonial history. Accordingly, the discipline endeavors to decolonize itself with questions about the power of definition and authorship, about the "crisis of representation" and questions about "Writing Culture" (Kaufmann 2013, p. 126 et seq.). Cultural studies as it exists today therefore calls into question research conducted about the other, which is to say the scientific objectification of the subject being studied. As a field, it counters this scientific "othering" (Fabian 1993, p. 337), as a production of otherness, and posits a postcolonial position in the search for new possibilities of collaborative, ethically acceptable knowledge production.

Inquiry-based learning in cultural studies thus consists of a critical-reflective process of a discovering acquisition of knowledge and production of knowledge within the context of teaching theoretical foundations, empirical tools and practical implementation. The cyclical course of an ethnographic research process is similar to the phase of inquiry-based learning, in which both theory and empiricism are linked and the process is not linear, but is to be understood as recursive, evolutive design (ibid., p. 45 et seq.), which repeatedly applies different steps to itself. By way of illustration (Table 25.1), the phase model of inquiry-based learning developed by Huber (2013, p. 248) is compared to the ethnographic research process (Kaufmann 2013, p. 131 et seq.). 
Table 25.1 Comparison of the phases of inquiry-based learning with the phases of ethnographic research

\begin{tabular}{|c|c|}
\hline $\begin{array}{l}\text { Phases of inquiry-based learning } \\
\text { (according to Huber 2013): }\end{array}$ & $\begin{array}{l}\text { Phases of cultural-scientific, ethnographic inquiry-based } \\
\text { learning (according to Kaufmann 2013): }\end{array}$ \\
\hline 1. Introduction & 1. Providing research access \\
\hline 2. Identifying a question & 2. Developing a question \\
\hline 3. Processing information & $\begin{array}{l}\text { 3. Defining the research design (Exposé relating to the state } \\
\text { of the research and the theory contexts) }\end{array}$ \\
\hline $\begin{array}{l}\text { 4. Acquiring methodological } \\
\text { knowledge }\end{array}$ & 4. Data collection \\
\hline 5. Developing a research design & $\begin{array}{l}\text { 5. Rendering the progression of the research as text (journal, } \\
\text { logs, transcriptions, documents) }\end{array}$ \\
\hline 6. Conducting a research activity & $\begin{array}{l}\text { 6. Data analysis and interpretation (mediation between } \\
\text { theoretical and field contexts with the aim of modifying and } \\
\text { expanding theories) }\end{array}$ \\
\hline $\begin{array}{l}\text { 7. Preparation and presentation of } \\
\text { the results }\end{array}$ & \multirow{2}{*}{$\begin{array}{l}\text { 7. Presentation of the research and its results (research } \\
\text { reports, publications, presentations, including reflection on } \\
\text { the procedure, the course of the relationship and one's own } \\
\text { role) }\end{array}$} \\
\hline 8. Reflection & \\
\hline
\end{tabular}

Source: Author's representation

\subsection{General Experiences with Inquiry-Based Learning in Cultural Studies}

The usual distinction between research and practice projects does not really apply to cultural studies (Kaufmann, 2015). This is because projects that relate to the transfer of scholarship to practice in cultural studies include parallel research projects and practice-oriented, application-oriented research projects. Students are involved in the research projects of the instructors through "cognitive apprenticeship" (Tremp 2005, p. 345). This means that they are involved in all scientific thinking and action processes. Cognitive apprenticeship, as a kind of "cognitive master teaching" (ibid.), introduces students and doctoral students to the scientific community, specialist discourses and research areas (Kaufmann 2013, 2015). Inquiry-based learning does not present the subject-specific characteristics as a conglomeration of knowledge to be passively received, nor does it teach students using a top-down approach; instead, students actively participate in the production of knowledge. Cognitive apprenticeship promotes "team-play" (Ghaffarizad et al. 2015) between instructors and students and particularly supports collaborative learning, since the teaching-learning processes become a common concern of instructors and students alike. They get to know each other better through joint research questions and goals, becoming mutually supportive, collaborative "accomplices" (Kaufmann and Koch 2015a). 
By integrating students into their research and what are termed transfer projects (Vermittlungsprojekte), it is possible to promote up-and-coming scholars, taking into account inequality factors. This is because instructors sensitize themselves to the different learning and research conditions of the students through student-oriented collaboration in inquiry-based learning. Thus, inquiry-based learning promotes dealing more consciously with diversity among students and instructors, and with discrimination and its factors during a course of study. Huber (2015) describes diversity among students and instructors on four levels, which I extend to six by adding the latter two:

- requirements, conditions and activities associated with teaching and learning,

- teaching-learning research forms (methods),

- interests of students and instructors,

- subject matter of teaching, learning and research,

- forms of communication and relationship,

- objectives of learning and research.

In inquiry-based learning in cultural studies, diversity is the subject of research, the topic of teaching, the methodological-didactic element and the basis for a mutual perception of instructors and students that is sensitive to difference and inequality. This involves the conscious handling of personal, professional and status-related differences between the students as well as among the instructors.

\subsection{Inquiry-Based Learning throughout the Learning Cycle}

The objective of cultural studies (shown here at the University of Bremen, for example) is directed both towards the acquisition of technical, theoretical, analytical, methodical and practical competencies, as well as what are known as "key competencies" in the fields of social affairs, ethics, diversity awareness and mediation. The acquisition of competency in the learning cycle within the "student lifecycle" corresponds to the processual ethnological research practice. The term "learning cycle" refers to processual, experience-based student learning, including the respective learning style. It travels in parallel to the student lifecycle. All activities related to studies are summarized under the concept of "student lifecycle," beginning with the application and admission of students for entry into a course of study, to their transition to working life and alumni work (Schulmeister 2007, p. 230). The curriculum is also designed in such a way that its building blocks can be related to the establishment of a research cycle:

In keeping with the entry into the student lifecycle, the learning cycle in the first academic year is dedicated to arriving within the course of study, the field and its community. After orientation week, students learn the central goals, questions and tasks of the discipline in introductory compulsory modules, and acquire technical basic skills for reading and writing texts, sharpen their senses for a research orientation, and practice the 
presentation of results. Introductions to basic questions are combined with exercises and small group work by the teaching organization in order to establish a relationship with the students right from the start, and to provide subject-oriented assistance.

Students subsequently attend courses on the subject classification system and in regional specializations as compulsory elective options in the second year of study, the core phase of the student lifecycle. In the third semester during this phase, they already acquire central research competencies through the intensive two-semester method training, which is implemented as a process of learning by doing research according to the learning cycle (Kaufmann 2013). Workshops support the writing of scientific texts and thereby attempt to take into consideration diversity among the students.

The final phase, which is the end phase of the student lifecycle in the third year of study, primarily supports independent work during and after graduation. This phase includes a practice module, major and minor modules in the compulsory elective area, a self-study module and, lastly, the final module. In the practical module, students complete at least 6 weeks of work placement in some field of cultural practice. In the self-study module, they deepen their selected focus and prepare themselves for the final thesis. The practice and self-study phase also leaves room for study or an internship abroad. The entire curricular course of the learning cycle along the student lifecycle, from introductions to the discipline and the independent testing of methods with the assistance of research workshops to independent inquiry-based learning, prepares students for an empirically or theoretically designed bachelor's thesis, the writing of which is supported by means of supervisory seminars and working groups. At the University of Bremen, the introduction of the regularly offered student conference "ResearchInsights" will not only present research results to a public audience, but will also put up issues and research settings for discussion, and train students in different forms of imparting knowledge.

\subsection{A Method Module as an Example}

Inquiry-based learning is already being implemented successfully in ethnologically based cultural studies, which considers the students' own research experience as a central element of academic studies when starting the bachelor's degree program with a large number of students (Kaufmann, 2013, 2015; Kaufmann and Koch 2015a, b). This will be explained briefly using the example of method training from the perspective of the individual responsible for the module. As stated by the German Rectors' Conference, " [...] the objectives and characteristics of inquiry-based learning can be realized especially well within the context of methodological training, since all of the central work steps of a research process as well as selected subject-related content and interdisciplinary competencies are essentially imparted by university instructors or acquired by students" HRKFachgutachten 2013, p. 75, translated). 


\subsubsection{What Are the Basic Conditions of the Module Subject?}

In the methodology foundation module of the bachelor's degree program in cultural studies at the University of Bremen, which students complete in the third semester, students acquire cultural research methods by means of ethnographic field research experience. Here, they go through a whole research process according to the phase models of inquiry-based learning that have been presented, which extends from searching for a suitable field of research, developing a research question, and collecting and evaluating the data to writing the research report and, if possible, publication thereof. The module (described in detail in Kaufmann 2013) is offered in the winter semester with over 100 students who have cultural studies as a major or complementary subject. The person responsible for the module prepares the conceptual basics, undertakes the organization and coordinates the teaching team. The team consists of five instructors and five students from the previous year as tutors.

The aim of the module is "to provide students with basic methodological training that enables them to carry out, evaluate and describe their own ethnological and cultural (field) research" (Modulhandbuch 2012). It makes it possible to become familiar with and test cultural science tools, stimulate research and questioning, and make the experience of an entire research process tangible. Ethical questions about researching with and about people are fundamental. Social learning and research, both in the team and individually, promote methodical, theoretical, (professionally) practical, academic, social and ethical competencies.

By researching current socio-politically relevant issues, students also move locally in different social fields off campus (Kaufmann 2015). They experience complex, diverse learning research situations and inductively investigate explorative case studies through encounters with people and subject areas. The research experiences are reflected in the journals and in the accompanying research workshops. By defining the research design and the exposé, the methodological steps of the data collection such as participant observation and interviews are defined and recorded in notes, logs and transcripts. The evaluation is carried through the analysis, triangulation and interpretation of the collected data. A research report is prepared and a transfer of the results sought where possible, for example through publications, in order to promote self-reflection, as well as reflection on the group work and methods reflection in the research process.

\subsubsection{How Is the Module Implemented?}

The lecture, which is as interactive as possible, with two semester hours per week, binds the module together. It introduces basic methods of cultural research and leads students to form research teams and to perform their own fieldwork. It establishes basic methods and techniques which are discussed, mediates between the reading of basic texts and students' own handling of the methods, and guides the individual research steps. In doing so, it supports the research process and helps to document, analyze, interpret and reflect on the 
central results thereof. The faculty and doctoral candidates also provide stimuli for the individual steps, ideally as directly as possible from the immediate research.

The lecture is supplemented by four research labs, which are conducted jointly by instructors and tutors for two semester hours per week. They accompany and support the research process. Students from the previous year serve as tutors, building on their own experiences. They support inquiry-based learning by means of their concrete experiences, redesign the module on an ongoing basis from the perspective of the student, and contribute significantly to quality assurance.

In the labs, the students work in teams on the research documents that they themselves have created. They go through the work steps together and discuss any problems that arise. Through the process-related work, the research reports are written on an ongoing basis throughout the semester. This does not proceed for all groups and fields of research in a manner that is equally effective. An openness to the various research conditions is therefore important here.

Working both individually and in teams, students implement the research steps in teams that are assembled such that they are as diverse as possible, ideally in groups of three and based on previous experience. In so doing, care should be taken to form teams based on research interests as much as possible so that everyone feels comfortable with their team. The teams then focus on a research topic, working together on access to the field and on a central question. This collaboration supports diversity awareness and mutual assistance. It is supplemented by the students' own work, both in the data collection as well as in the reading and writing of texts. In addition, the internet platform "Stud.IP" is used as a teaching and learning tool. It also serves for framing and bundling as well as communication between the various levels and persons involved. On the e-learning platform "Stud.IP," students can work together on their data and texts.

\subsubsection{What Is the Purpose of Conducting Research?}

As a rule, students choose their research topics and fields themselves. However, instructors offer them opportunities to establish connections to their own research topics and fields in the sense of cognitive apprenticeship and collaborative, intricate forms of knowledge production. For example, a study on the diversity of students was conducted on the campus of the University of Bremen (Kaufmann 2013). Here, based on a joint decision, the student research dovetailed with the researchers' research on "Diversity in Organisationen Unternehmen und Hochschulen" ("Diversity in Organizational Businesses and Institutions of Higher Learning"). They contrasted "Quest," the student survey on diversity at the Charitable Center for Higher Education Development (Centrum für Hochschulentwicklung, $\mathrm{CHE}$ ), with diversity categories and references inductively developed from the student perspective. Through this research with students from other disciplines, study-relevant factors and diversity categories were surveyed which go far beyond the current categories of inequality. Inquiry-based learning on diversity was used to sensitize researchers, 
assistants and representatives of the institution to the different lifestyles as well as study and learning conditions among the students. The results were incorporated into the diversity processes of the University of Bremen.

Appropriate power-critical approaches to dealing with research ethics, based on academic tradition, raise fundamental questions about the forms of social and cultural coexistence and the norms, values and traditions of our rapidly changing, complex societies. Students' research revolves around fields of research on migration, refugees and asylum, artists and cultural professionals, subcultures and interest groups, social institutions and projects, cuts in social services and forms of protest, as well as social norms, stigmas and discrimination. The focalized areas, groups and institutions where societal problems arise correspond to a part of the spectrum in which cultural scholars later work. Instructors and students enter the social fields with this research orientation and the collaborative forms of knowledge generation. Inquiry-based learning can therefore be made a "link between a research and a vocational orientation" (Kaufmann 2015). It promotes the transfer between scholarship and society as a reciprocal process. After all, cultural studies needs these fields of practice as fields of research and work, and society, in turn, needs the concepts, methods and research that arises from scholarship.

\subsection{Outlook for Inquiry-Based Learning in Cultural Studies: What Needs to Be Done?}

Inquiry-based learning in cultural studies requires communicative and developmental spaces for good collaboration within the teaching team and with students, as well as space for negotiating transdisciplinary and transcultural processes (Kaufmann and Satilmis 2015). In principle, there is an equal need for reaching an understanding on the notions of subject-cultural specific forms of inquiry-based learning and for didactic training. According to the reformed degree program structure and modularization, inquiry-based learning processes with a corresponding scope for the heterogeneous student body are possible, although the module structure makes longer research phases more difficult. We therefore need to explore how longer phases can be made possible. It may be necessary to redesign module plans.

When individual modules attempt to keep the emphasis on processuality throughout the research, this makes them demanding and they tend to become overloaded. Working on curricular interlocking, this works against the "Zurich framework" model (Hildbrand and Tremp 2012, see also Mieg, in this volume). The theoretical and empirically oriented modules are easier to link, for example. Evaluation and accompanying research is needed in order to support the curricular integration of the modules and the way the student lifecycle fits together with the learning cycle. In cultural studies at the University of Bremen, for example, an accompanying research project is based on the question of how the student lifecycle can fit together with the learning cycle. The micro-, meso- and macro-levels of the design of the teaching-learning processes are systematically linked when implementing inquiry-based learning in cultural studies: 
At the micro-level, at issue is the implementation of individual steps and elements of inquiry-based learning so that they are made tangible in their context as a research and learning cycle. In so doing, it is always about setting the framework and balancing guidelines with decision-making and experience opportunities of the students. With appropriate guidance and support, it increases students' motivation to study by fostering self-reliance. Subject-oriented work performed in small groups supports the sensitization of personal teaching and learning conditions and thus promotes educational justice.

At the meso-level, it is about explicating, documenting and communicating the concept of the degree program. In addition, individual modules can be relieved by harmonizing them better within the meaning of the Zurich framework. They can then cover partial aspects of the research and do not need to map the whole research questionnaire. Tutorials and research workshops can be expanded into free research laboratories. Relations with research partners, fields and topics can be sustained for long-term research as permanent field sites in institutions and neighborhoods. The aim is to academically accompany urban transformation processes and to contribute to the design of processes through collaborative research. These measures must be embedded in the quality cycles and degree program developments.

At the macro-level, there are links with university management and its planning. A greater number of instructors, sufficient existing rooms and connections between university planning, subject didactics and the everyday activities of teaching and learning are needed. As it is work-intensive for instructors to develop different courses and to respond to needs individually, inquiry-based learning requires more intensive supervision. Thus, structurally, priority is given to having sufficient resources and the smallest possible support ratio for inquiry-based learning.

\section{References}

Breidenstein, G./Hirschauer, S./Kalthoff, H./Nieswand, B. (2013). Ethnografie. Die Praxis der Feldforschung. Konstanz/München: UVK Verlagsgesellschaft.

Fabian, J. (1993). Präzenz und Repräsentation. Die Anderen und das anthropologische Schreiben. In E. Berg/M. Fuchs (Hrsg.), Kultur, soziale Praxis, Text. Die Krise der ethnographischen Repräsentation (S. 335-364). Frankfurt a.M.: Suhrkamp.

Ghaffarizad, K./Kaufmann, M. E./Koch, H./Kurzawski, B./Reuter, A./Seufert, P. (2015). Forschendes Lernen als Team-Play. Gemeinsamer Bericht von Studierenden und Lehrenden über den Tag der Lehre 2014 am Institut für Ethnologie und Kulturwissenschaft. Resonanz. Magazin für Studium und Lehre an der Universität Bremen, 3, 9-14.

Hildbrand, T./Tremp, P. (2012). Forschungsorientiertes Studium - universitäre Lehre: Das »Zürcher Framework « zur Verknüpfung von Lehre und Forschung. In T. Brinker/P. Tremp (Hrsg.), Einführung in die Studiengangsentwicklung (S. 101-116). Bielefeld: Bertelsmann.

HRK-Fachgutachten (2013). Employability und Praxisbezüge im wissenschaftlichen Studium. Retrieved am 14 June 2015 from http://www.hrk-nexus.de/fileadmin/redaktion/hrk-nexus/07Downloads/07-02-Publikationen/Fachgutachten_Employability.pdf

Huber, L. (2013). Methodische Anregungen für den Umgang mit pragmatischen Schwierigkeiten im Forschenden Lernen. In L. Huber/M. Kröger/H. Schelhowe, Forschendes Lernen als 
Profilmerkmal einer Universität. Beispiele aus der Universität Bremen (S. 247-255). Bielefeld: UniversitätsverlagWebler.

Huber, L. (2015). Vielfalt in der Lehre - Heterogenität als Chance. Forschendes Lernen als ein Weg. In M. E. Kaufmann/K. Ghaffarizad/F. Hoffmann/F. Suckut (Hrsg.), Diversity @ Uni Bremen: exzellent und chancengerecht?! Dokumentation (S. 27-29). Bremen: bik.

Kaufmann, M. E. (2013). »Wir haben selbst neue Wissenszusammenhänge geschaffen!« Forschendes Lernen zu "Diversity" in der Kulturwissenschaft. In L. Huber/M. Kröger/ H. Schelhowe (Hrsg.), Forschendes Lernen als Profilmerkmal einer Universität. Beispiele aus der Universität Bremen (S. 123-142). Bielefeld: Universitätsverlag Webler.

Kaufmann, M. E. (2015). Forschendes Lernen als Bindeglied zwischen Forschungs- und Berufsorientierung in geisteswissenschaftlichen Studiengängen. In P. Tremp (Hrsg.), Forschungsorientierung und Berufsbezug im Studium. Blickpunkt Hochschuldidaktik, Buchreihe der dghd (S. 151-170). Bielefeld: Bertelsmann.

Kaufmann, M. E./Koch, H. (2015a). Die Lehrenden als Kompliz_innen im forschenden Lernprozess. In K. Rheinländer (Hrsg.), Ungleichheitssensible Hochschullehre (S. 219-236). Wiesbaden: Springer VS.

Kaufmann, M. E./Koch, H. (2015b). Forschendes Lernen zum Umgang mit Heterogenität als Instrument in der qualitativen Evaluationsforschung. In S. Harris-Hümmert/ L. Mitterauer/P. Pohlenz (Hrsg.), Heterogenität der Studierendenschaften: Herausforderung für die Qualitätsentwicklung in Lehre und Studium, neuer Fokus für die Evaluation? (S. 113-128). Bielefeld: UniversitätsverlagWebler.

Kaufmann, M. E./Satilmis, A. (2015). In-Between Disciplines. Forschendes Lernen als Frame für die Gestaltung transkultureller und -disziplinärer Lernräume. In H. Schelhowe/M. Schaumburg JJ. Jasper (Hrsg.), Teaching is Touching the Future. Academic Teaching within and across disciplines (S. 349-352). Bielefeld: UniversitätsverlagWebler.

Marcus, G. E. (1998). Ethnography trough Thick and Thin. Princeton: Princeton University Press.

Modulhandbuch (2012). Bachelorstudiengang Kulturwissenschaft. Bremen: Universität Bremen.

Schulmeister, R. (2007). Der Student Lifecycle als Organisationsprinzip für E-Learning. In R. Keil, M. Kerres/R. Schulmeister (Hrsg.), eUniversity - Update Bologna (S. 45-77). Münster: Waxmann.

Tremp, P. (2005). Verknüpfung von Lehre und Forschung. Eine universitäre Tradition als didaktische Herausforderung. Beiträge zur Lehrerbildung, 23/3, 339-348.

Open Access This chapter is licensed under the terms of the Creative Commons AttributionNonCommercial-NoDerivatives 4.0 International License (http://creativecommons.org/licenses/bync-nd/4.0/), which permits any noncommercial use, sharing, distribution and reproduction in any medium or format, as long as you give appropriate credit to the original author(s) and the source, provide a link to the Creative Commons licence and indicate if you modified the licensed material. You do not have permission under this license to share adapted material derived from this chapter or parts of it.

The images or other third party material in this chapter are included in the chapter's Creative Commons licence, unless indicated otherwise in a credit line to the material. If material is not included in the chapter's Creative Commons licence and your intended use is not permitted by statutory regulation or exceeds the permitted use, you will need to obtain permission directly from the copyright holder. 